\title{
Perfil Clínico e Epidemiológico de Universitários com Migrânea Durante a Pandemia COVID19
}

\author{
Alcylene Carla de Jesus dos Santos ${ }^{(D)}$, Acássia Benjamim Leal Pires ${ }^{(D)}$, Ana Patricia Pascoal Queiroz ${ }^{\mathbb{D}}$, \\ Luana de Oliveira Leite ${ }^{(D)}$, Maria da Glória Canto de Sousa
}

Universidade do Estado da Bahia.

\section{Introdução}

Os serviços que atendem pacientes com cefaleia precisam se adaptar a este momento pandêmico, minimizando consultas presenciais, mas mantendo os cuidados em saúde, orientando os pacientes a aderirem ao tratamento sugerido, e evitando gatilhos desencadeadores da migrânea.

\section{Objetivo}

Descrever o perfil clínico e epidemiológico de universitários com migrânea durante a pandemia COVID19.

\section{Material e Métodos}

Foi realizado um estudo descritivo de corte transversal entre acadêmicos de uma Universidade de Salvador, Bahia, no período de dezembro de 2020 a junho de 2021 . Foram convocados por meio de aplicativo de mensagem instantânea WhatsApp ${ }^{R}$ (WhatsApp Inc. Facebook Inc.) e direcionados via link para acesso ao Termo de Consentimento Livre e Esclarecido (TCLE), preenchidos via aplicativo de gerenciamento de pesquisa - Google Forms (Google LLCR, Califórnia, Estados Unidos). Esta pesquisa foi aprovada pelo Comitê de Ética em Pesquisa 4.351.573.

\section{Resultados}

Dentre os 83 universitários entrevistados 85,5\% apresentaram migrânea, 89,2\% eram do sexo feminino, com média de idade de 25 anos (+/- 6,9), 81,9\% solteiros e 41\% de cor preta. Dentre os entrevistados, 13,3\% apresentaram dificuldade em abrir a boca, 30,10\% sentiam dor na região de têmporas ou próximo ao ouvido durante a mastigação, fonação ou deglutição; e 27,7\% referiram ruídos ao mastigar falar ou bocejar, 55,4\% cursaram com cervicalgia, 53\% apresentaram rigidez no pescoço e 66,3\% referiram dor irradiada para os braços. 15,5\% apresentaram diagnóstico de COVID, 55,5\% apresentaram cervicalgia. $\bigcirc$ consumo de medicamentos sintomáticos para migrânea passou de menos de uma vez ao mês $(45,8 \%)$ para 1 a 4 vezes ao mês $(60,2 \%)$.

\section{Conclusões}

O perfil clínico e epidemiológico de universitários com migrânea durante a pandemia COVID 19 foram mulheres jovens, solteiras, com sinais e sintomas de DTM e cervicalgia.

Palavras-chave: Migrânea, COVID19, Perfil 